\title{
Regioselective openings of proximally sulfato-capped cyclodextrins
}

\author{
Matthieu Jouffroy, ${ }^{a}$ Rafael Gramage-Doria, ${ }^{a}$ Dominique Armspach, ${ }^{a}{ }^{a}$ Dominique Matt, ${ }^{* a}$ \\ and Loïc Toupet ${ }^{b}$
}

\section{Received (in $X X X, X X X) X t h X X X X X X X X X 20 X X$, Accepted $X$ th $X X X X X X X X X 20 X X$ \\ DOI: $10.1039 / b 000000 x$}

Sulfato groups capping one or two pairs of adjacent glucose units in methylated cyclodextrin $(\mathrm{CD})$ derivatives have been found to undergo regioselective openings with various 10 nucleophiles; the reported methodology opens the way to the efficient synthesis of tridifferentiated $\alpha$ - and $\beta$-cyclodextrins that constitute key starting materials for the preparation of heteropolydentate cavitands.

Naturally-occurring cyclodextrins (CDs) are cyclic 15 oligosaccharides made up of six, seven and eight equivalent $\alpha$ 1,4-linked glucopyranose units, respectively, for the most common ones, $\alpha-, \beta$ - and $\gamma$-CD. ${ }^{1}$ Because of their non-toxicity and their exceptional host-guest properties in water, ${ }^{2,3}$ they have found a wide range of applications in fields as diverse as drug 20 formulation, ${ }^{4}$ biomimetic chemistry ${ }^{5,6}$ and catalysis. ${ }^{7-9}$ Their chemical modification ${ }^{10,11}$ has also attracted a great deal of attention as access to tailor-made CDs responding to specific requirements becomes possible if some of the hydroxyl groups that decorate the $\mathrm{CD}$ torus can be substituted at given locations.

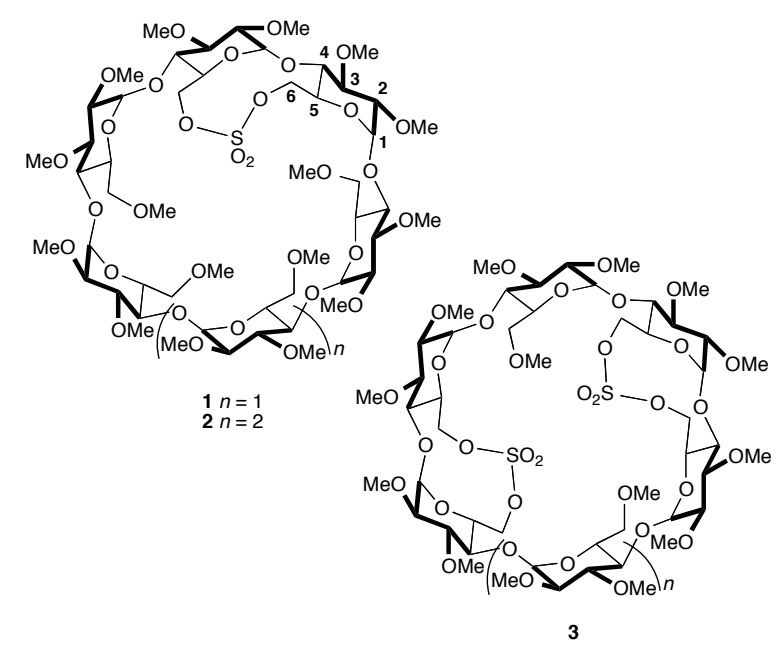

However, because of the highly symmetrical nature of the native CDs, differentiating their numerous identical hydroxyl groups remains a challenge that has only been met with success recently. One of the most elegant approaches relies on the partial and 30 regiospecific removal of bulky benzyl protecting groups from the narrower rim of perbenzylated CDs, in which steric effects are maximized, by DIBAL. ${ }^{12-15}$ Steric hindrance generated by $O$ benzyl groups has also proved pivotal to the regiospecific opening through nucleophilic attack of a sulfato group capping 35 the A,D units of a benzylated $\beta$-CD. ${ }^{16,17}$ Recently, we have shown that proximal capping of methylated $\alpha$ - and $\beta$-CD scaffolds with sulfato units can be achieved straightforwardly. ${ }^{18}$ In this paper we show that the cyclic sulfates $\mathbf{1 - 3}$ can be used effectively for the synthesis of tridifferentiated CDs.

40 Achieving a highly regioselective nucleophilic attack on the sulfato bridges is here much more of a challenge as bulky benzyl groups, which might facilitate discrimination of the attack position, are no longer present. We were delighted to observe that regiospecific opening of sulfato groups took place both in the 45 singly and doubly capped $\alpha$-CDs ( 1 and 3 respectively) provided the nucleophile is not only bulky, but also powerful enough for the reaction to occur at low temperature. Thus, treatment of $\mathbf{1}$ with lithium diphenylphosphide at $-78^{\circ} \mathrm{C}$ and subsequent phosphorus protection with $\mathrm{BH}_{3}$ followed by hydrolysis of the 50 sulfate anion afforded cavitand 5a in $97 \%$ overall yield (Scheme 1; Table 1 , entry 1 ).
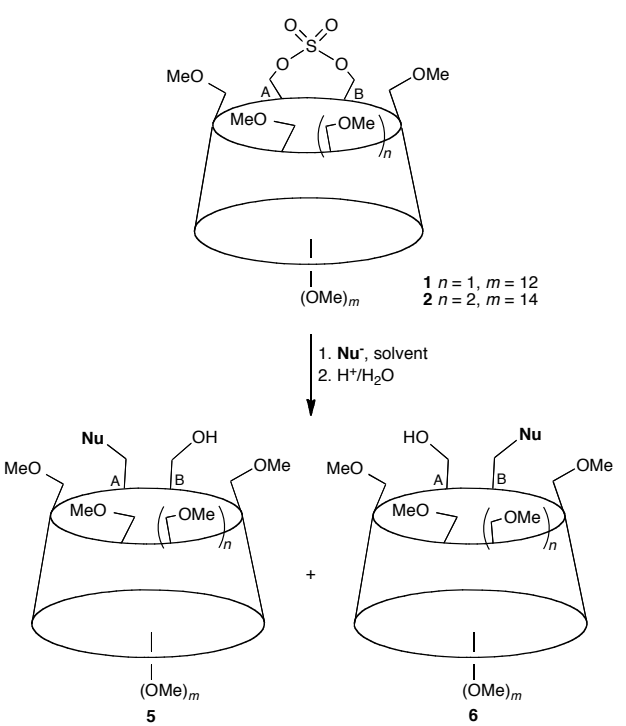

Scheme 1 Reactivity of monosulfates 1 and 2. 
The $C_{2}$-symmetric, diphosphine-borane 7a (Scheme 2; Table 1, entry 8 ) was obtained from 3 according to the same procedure in $60 \%$ yield, as a single regioisomer. Both 5a and 7a bear three different, pro-coordinating groups at precise locations on the $\mathrm{CD}$ 5 scaffold.

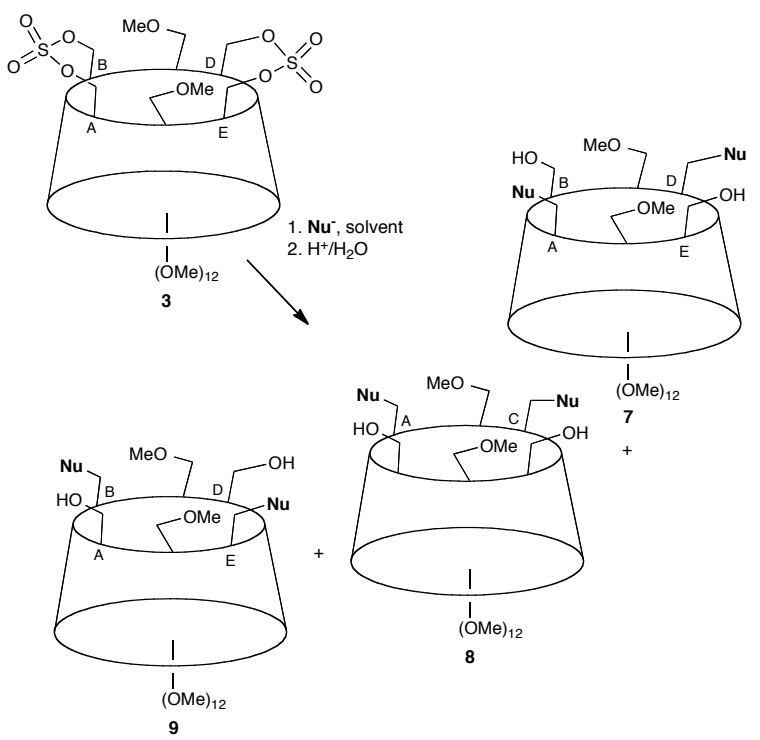

Scheme 2 Reactivity of disulfate 3 .

Careful examination of the X-ray crystal structure of disulfate 3 10 gives a strong indication of which carbon atoms are more susceptible to nucleophilic substitution (Fig. 1). ${ }^{18}$ The C-6 ${ }^{\mathrm{A}}$ is clearly available for backside attack, whereas the approach of the nucleophile on $\mathrm{C}-6^{\mathrm{B}}$ is partially blocked by neighbouring glucose unit $\mathrm{C}$ (the same comment holds for their symmetric counterparts, ${ }_{15} \mathrm{C}-6^{\mathrm{D}}$ and $\mathrm{C}-6^{\mathrm{E}}$, respectively).

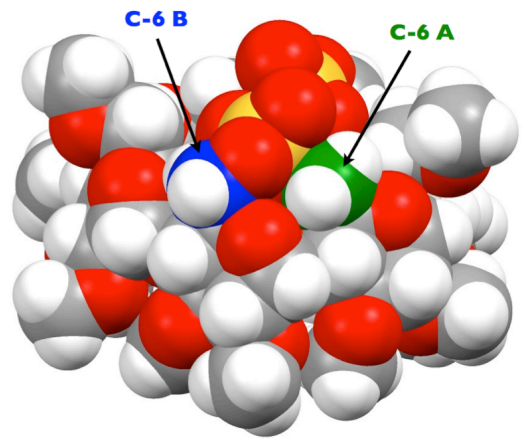

Fig. 1 X-ray structure of the $C_{2}$ disulfate doubly capped derivative 3 (sideview of the $C D$ scaffold). This spacefill view shows that the $C-6^{A}$ atom (in green) is perfectly positioned for nucleophilic backside attack 20 compared to its $\mathrm{C}-6^{\mathrm{B}}$ counterpart (in blue). The solvent molecules are not shown.

Full NMR assignment of phosphine-borane 5a using 2D COSY, TOCSY, HMQC and ROESY NMR experiments confirmed glucose unit $\mathrm{A}$ as being the only one having undergone 25 nucleophilic attack. In the case of doubly capped species, full NMR assignment of oxidized diphosphine $\mathbf{1 0}$ as well as a singlecrystal X-ray diffraction study (Fig. 2) carried out for 7a confirmed the phosphination of the A and D glucose units.

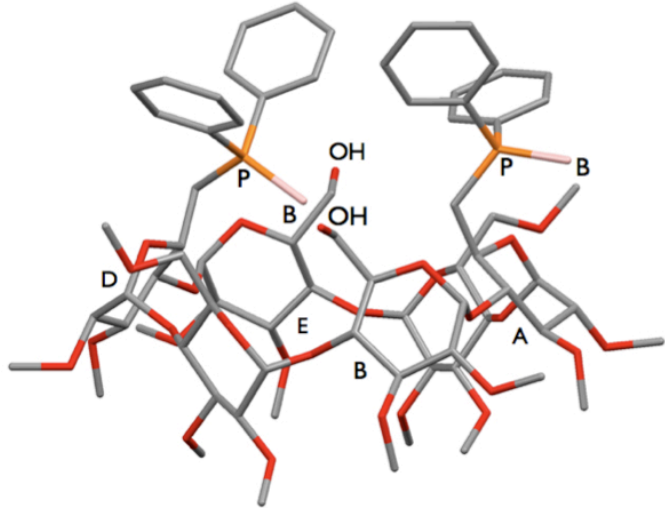

Fig. 2 X-ray structure of the diphosphine borane adduct 7 a (side30 view). This structure shows one of the $\mathrm{P}^{-\mathrm{BH}_{3}}$ entities plunging into the cavity. The solvent molecules are not shown.

Interestingly, in the solid state, a $\mathrm{BH}_{3}$ moiety is nested at the cavity entrance, its upper part being protected by the four $\mathrm{PPh}$ 35 rings, so as to lead to full encapsulation of this borane unit. The second $\mathrm{BH}_{3}$ unit is pushed away from the $\mathrm{CD}$.

Table 1 Experimental conditions for the opening of 1, 2 and 3.

\begin{tabular}{|c|c|c|c|c|c|c|c|}
\hline Entry & $\mathrm{CD}$ & $\mathrm{Nu}^{-a}$ & $\mathrm{n}^{b}$ & Solvent & $\begin{array}{c}T \\
\left({ }^{\circ} \mathrm{C}\right)\end{array}$ & $\begin{array}{c}\text { Product } \\
\text { [Yld (\%)] }\end{array}$ & $\begin{array}{c}r e \\
(\%)^{c}\end{array}$ \\
\hline 1 & 1 & $\mathrm{Ph}_{2} \mathrm{P}$ & 2.2 & THF & -78 & $\begin{array}{c}\mathbf{5 a} \\
{[97]^{e}}\end{array}$ & 100 \\
\hline 2 & 1 & & 4 & DMF & 0 & $\begin{array}{c}\mathbf{5 b}+\mathbf{6 b} \\
{[92]^{d}}\end{array}$ & 87 \\
\hline 3 & 1 & $\mathrm{~N}$ & 5 & DMF & 50 & $\begin{array}{c}\mathbf{5 c}+\mathbf{6 c} \\
{[98]^{d}}\end{array}$ & 59 \\
\hline 4 & 1 & $\mathrm{~N}_{3}$ & 4 & DMF & 0 & $\begin{array}{c}\mathbf{5 c}+\mathbf{6 c} \\
{[94]^{d}}\end{array}$ & 67 \\
\hline 5 & 1 & & 4 & DMF & 0 & $\begin{array}{c}\mathbf{5 d}+\mathbf{6 d} \\
{[91]^{d}}\end{array}$ & 50 \\
\hline 6 & 2 & & 2.2 & THF & -78 & $\begin{array}{c}\mathbf{5 e}+\mathbf{6 e} \\
{[95]^{e}}\end{array}$ & 22 \\
\hline 7 & 2 & & 12 & DMF & 0 & $\begin{array}{c}\mathbf{5 f}+\mathbf{6 f} \\
{[76]^{d}}\end{array}$ & 23 \\
\hline 8 & 3 & & 3.5 & THF & -78 & $\begin{array}{c}7 \mathbf{a} \\
{[60]^{e}}\end{array}$ & 100 \\
\hline 9 & 3 & & 8 & DMF & 0 & $\begin{array}{c}\mathbf{7 b}+\mathbf{8 b} \\
{[82]^{d}}\end{array}$ & 33 \\
\hline
\end{tabular}

${ }^{a}$ Nucleophile; ${ }^{b}$ Equivalents of nucleophile; ${ }^{c}$ Regioisomeric excess 40 determined by ${ }^{1} \mathrm{H}$ NMR and/or HPLC, $r e=(|[5]-[6]|) /([5]+[6])$ for entries $1-7, r e=(|[7]-[8]|) /([7]+[8])$ for entries 8 and $9 ;{ }^{d}$ Yield of regioisomers mixture after acidic work-up, ${ }^{e}$ Yield of regioisomers mixture after borane protection and acidic work-up. Compounds $5 \mathbf{a}, \mathbf{5 e}, \mathbf{6 e}$, and $7 \mathbf{a}$ are $\mathrm{BH}_{3}-$ protected phosphines.

In stark contrast with the results obtained by Bols, ${ }^{16}$ moderate regioselectivities were observed with the small azide and thioacetate nucleophilic anions (Table 1, entries 3-5). Not surprisingly, the opening reaction with sodium azide is so temperature sensitive. Cooling the same reaction mixture from $50^{\circ} \mathrm{C}$ to $0^{\circ} \mathrm{C}$ increased the regioisomeric excess by $8 \%$ (Table 1 , entry 4), confirming that the reaction operates under kinetic control. The regioselectivity was further improved by using the 
medium-sized phthalimide anion instead of azide (Table 1, entry 2). Thus, tridifferentiated CD $\mathbf{5 b}$, which could be separated from its regioisomer $\mathbf{6 b}$ by standard column chromatography, was recovered in $87 \%$ isolated yield vs. $5 \%$ yield for $\mathbf{6 b}$. An X-ray ${ }_{5}$ crystal structure of $\mathbf{5 b}$ proved that the nucleophilic attack had once again taken place mainly on the A glucose unit of sulfatocapped CD 1 (Fig. 3). Similarly to the X-ray crystal structure of $7 \mathbf{a}$, the bulky grafted group, in this case phthalamide, closes the primary face without penetrating the cavity.

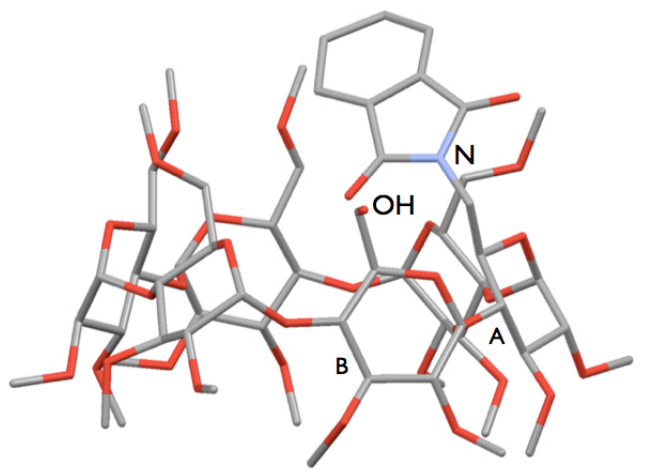

Fig. 3 X-ray structure of the major regioisomer of phthalimide $\mathbf{5 b}$ (side-view). The solvent molecules are not shown.

Performing the same reaction with the doubly capped CD 3 15 (Scheme 2; Table 1, entry 9) gave $C_{2}$-symmetric $7 \mathbf{b}$ as the major regioisomer (isolated yield $50 \%$ ). The only possible $C_{1^{-}}$ symmetric regioisomer $(\mathbf{8 b})$ was isolated in $28 \%$ yield, but the presence of the second conceivable $C_{2}$-symmetric species $(9 \mathbf{b})$ was not detected. This is hardly surprising as the formation of the 20 latter is strongly disfavoured considering the outcome of the reaction between $\mathbf{1}$ and potassium phthalimide. Again, full assignment by NMR spectroscopy confirmed the same substitution pattern in $\mathrm{N}$-containing $\mathbf{7 b}$ as in P-containing $\mathbf{7 a}$. Note that tridifferentiated CD $\mathbf{7 b}$ constitutes a key intermediate 25 for accessing $C_{2}$-symmetric nitrogen ligands as the phthalimide groups may easily be converted into primary amino groups. Similar sulfate openings were also conducted on singly capped $\beta$ CD 2, but much lower regioselectivities were observed (Scheme 1; Table 1, entry 6-7), even in the presence of lithium 30 diphenylphosphide at $-78^{\circ} \mathrm{C}$. It seems that the higher radius of curvature or/and flexibility of the methylated $\beta-\mathrm{CD}$ scaffold compared to its $\alpha$-CD counterpart results in a poorer differentiation between the two $\mathrm{CD} C-6^{\mathrm{A}}$ and $\mathrm{C}-6^{\mathrm{B}}$ carbon atoms involved in the cyclic sulfate opening.

\section{${ }_{35}$ Conclusions}

In summary, sulfato groups capping adjacent glucose units of methylated CDs have been shown to undergo regioselective openings with various nucleophiles. This methodology is currently extended to A,C and A,D-capped species in order to 40 access new tridifferentiated CDs aimed at the constitution of a library of heteropolydendate $\mathrm{CD}$ ligands for asymmetric homogeneous catalysis and molecular recognition.

The authors are grateful to the Région Alsace and the Centre International pour la Recherche aux Frontières de la Chimie
${ }_{45}$ (CIRFC) for financial support (grant for M.J.).

\section{Notes and references}

${ }^{a}$ Laboratoire de Chimie Inorganique Moléculaire et Catalyse, Institut de Chimie UMR 7177 CNRS, Université de Strasbourg, 67008 Strasbourg Cedex, France.

50 E-mail: d.armspach@unistra.fr,dmatt@unistra.fr; Fax: +33368851637

${ }^{b}$ Institut de Physique de Rennes UMR 6251 CNRS,

Université de Rennes 1, Campus de Beaulieu - Bâtiment 11A,

35042 Rennes cedex, France.

$\dagger$ Electronic Supplementary Information (ESI) available: synthesis and 55 characterization data. See DOI: $10.1039 / \mathrm{b} 000000 \mathrm{x} /$

† Crystal data for $\mathrm{C}_{60} \mathrm{H}_{95} \mathrm{NO}_{31} \cdot 0.5 \mathrm{CH}_{2} \mathrm{Cl}_{2} \cdot \mathrm{H}_{2} \mathrm{O} \cdot 1.5 \mathrm{C}_{5} \mathrm{H}_{12}$ $\left(\mathbf{5} \cdot \mathrm{BH}_{3} \cdot 0.5 \mathrm{CH}_{2} \mathrm{Cl}_{2} \cdot \mathrm{H}_{2} \mathrm{O} \cdot 1.5 \mathrm{C}_{5} \mathrm{H}_{12}\right), M_{r}=1495.07$; monoclinic; $P 2_{1} ; a=$ $15.2970(10), b=15.7262(8), c=16.6710(10) \AA, \beta=90.778(6)^{\circ} ; V=$ 4010.1(4) $\AA^{3} ; Z=2 ; \rho_{\text {calcd }}=1.238 \mathrm{Mg} \cdot \mathrm{m}^{-3} ; \lambda\left(\mathrm{Mo}_{\mathrm{K}_{u}}\right)=0.71073 \AA ; \mu=$ $600.129 \mathrm{~mm}^{-1} ; F(000)=1608 ; T=120 \mathrm{~K} ; 917$ variables and 7789 observations with $I>2.0 \sigma(I) ; R=0.0680, R_{\mathrm{W}}=0.1911$, and $S_{\mathrm{w}}=0.830$; $\Delta \rho<0.929$ e. $\AA^{-3}$. CCDC 826891 . For crystallographic data in CIF or other electronic format see DOI: $10.1039 / \mathrm{b} 000000 \mathrm{x} /$

$\S$ Crystal data for $\mathrm{C}_{74} \mathrm{H}_{112} \mathrm{~B}_{2} \mathrm{O}_{28} \mathrm{P}_{2} \cdot 3 \mathrm{CH}_{2} \mathrm{Cl}_{2} \cdot 1.5 \mathrm{C}_{5} \mathrm{H}_{12}$ $65\left(7\left(\mathrm{BH}_{3}\right)_{2} \cdot 3 \mathrm{CH}_{2} \mathrm{Cl}_{2} \cdot 1.5 \mathrm{C}_{5} \mathrm{H}_{12}\right), M_{r}=1896.19$; orthorhombic; $P 2_{1} 2_{1} 2_{1} ; a=$ 16.0969(4), $b=22.4367(5), c=27.7517(7) \AA ; V=10022.8(4) \AA^{3} ; Z=4$; $\rho_{\text {calcd }}=1.257 \mathrm{Mg} \cdot \mathrm{m}^{-3} ; \lambda\left(\mathrm{Mo}_{\mathrm{K} a}\right)=0.71073 \AA ; \mu=0.274 \mathrm{~mm}^{-1} ; F(000)=$ 4036; $T=120 \mathrm{~K} ; 1029$ variables and 8413 observations with $I>2.0 \sigma(I)$; $R=0.0935, R_{\mathrm{W}}=0.2645$, and $S_{\mathrm{w}}=0.932 ; \Delta \rho<0.658$ e. $\AA^{-3}$. CCDC

70 822184. For crystallographic data in CIF or other electronic format see DOI: $10.1039 / \mathrm{b} 000000 \mathrm{x} /$

1 J. Szejtli, Chem. Rev., 1998, 98, 1743-1753.

2 K. A. Connors, Chem. Rev., 1997, 97, 1325-1357.

753 M. V. Rekharsky and Y. Inoue, Chem. Rev., 1998, 98, 1875-1917.

4 K. Uekama, F. Hirayama, and T. Irie, Chem. Rev., 1998, 98, 20452076.

5 R. Breslow and S. D. Dong, Chem. Rev., 1998, 98, 1997-2011.

6 J. Bjerre, C. Rousseau, L. Marinescu, and M. Bols, Appl. Microbiol. 80 Biotecnol., 2008, 81, 1-11.

7 H. Bricout, F. Hapiot, A. Ponchel, S. Tilloy, and E. Monflier, Curr. Org. Chem., 2010, 14, 1296-1307.

8 F. Hapiot, A. Ponchel, S. Tilloy, and E. Monflier, C. R. Chimie, 2011, 14, 149-166.

${ }_{85} 9$ C. Yang, C. Ke, W. Liang, G. Fukuhara, T. Mori, Y. Liu, and Y. Inoue, J. Amer. Chem. Soc., 2011, 133, 13786-13789.

10 A. K. Khan, P. Forgo, K. J. Stine, and V. T. D'Souza, Chem. Rev., 1998, 98, 1977-1996.

11 E. Engeldinger, D. Armspach, and D. Matt, Chem. Rev., 2003, 103, 4147-4172.

12 A. J. Pearce and P. Sinaÿ, Angew. Chem. Int. Ed., 2000, 39, 36103612 .

13 T. Lecourt, A. Herault, A. J. Pearce, M. Sollogoub, and P. Sinaÿ, Chem. Eur. J., 2004, 10, 2960-2971.

9514 O. Bistri, P. Sinaÿ, J. J. Barbero, and M. Sollogoub, Chem. Eur. J., 2007, 13, 9757-9774.

15 M. Sollogoub, Eur. J. Org. Chem., 2009, 1295-1303.

16 M. Petrillo, L. Marinescu, C. Rousseau, and M. Bols, Org. Lett., 2009, 11, 1983-1985.

10017 M. Petrillo, L. Marinescu, and M. Bols, J. Incl. Phenom. Macrocycl. Chem. , 2011, 69, 425-431.

18 R. Gramage-Doria, D. Rodriguez-Lucena, D. Armspach, C. Egloff, M. Jouffroy, D. Matt, and L. Toupet, Chem. Eur. J. , 2011, 17, 39113921. 